\title{
RE-EVALUATING SATELLITE SOLAR POWER SYSTEMS FOR EARTH
}

\author{
Geoffrey A. Landis \\ NASA John Glenn Research Center \\ 21000 Brookpark Road \\ $\mathrm{m} / \mathrm{s} \mathrm{302-1}$ \\ Gleveland, $\mathrm{OH} 44135$
}

\begin{abstract}
The Solar Power Satellite System is a concept to collect solar power in space, and then transport it to the surface of the Earth by microwave (or possibly laser) beam, where it is converted into electrical power for terrestrial use. The recent increase in energy costs, predictions of the near-term exhaustion of oil, and prominence of possible climate change due to the "greenhouse effect" from burning of fossil fuels has again brought alternative energy sources to public attention, and the time is certainly appropriate to reexarnine the economics of space based power. Several new concepts for Satellite Power System designs were evaluated to make the concept more economically feasible.
\end{abstract}

\section{INTRODUCTION}

\section{Background}

In 1968, Peter Glaser, then of Arthur D. Little, proposed the concept of a Space Solar Power Satellite as a means to solve the problem of providing energy for terrestrial use [1]. Glaser's proposal was to place a large $\left(-10 \mathrm{~km}^{2}\right)$ solar array in geosynchronous orbit, and then to transmit power to the ground using a microwave beam $[1,2]$. This is shown in schematic in fig. 1 . The beamed power is received on the ground by a rectifying antenna, or "rectenna," which converts the microwaves to DC electrical power at a DC-to-DC efficiency of roughly $80 \%$.

By locating the solar array in orbit, rather than on the ground, the array has the advantage of continuous full sunlight, without the day-night cycle, atmospheric attenuation, or clouds to interrupt power. A space solar array produces roughly 10 times more power than the same array in a low-insolation location such as the Northeast, or about four times more power than the same array at a high-insolation location such as the southwest.

Although significant technical barriers to implementing the concept existed, both then and now, the energy crisis of the late 1970 s made the U.S. Department of Energy and NASA take the concept seriously enough that a feasibility study was done; and a conceptual "baseline" design for a Satellite Solar Power system was made [3]. This conceptual study was evaluated by the U.S. Office of Technology Assessment, who concluded that the concept was attractive, but could not be economically implemented with the technology of the time [4]. The report suggested re-evaluating the concept in ten years time.
In 1995, a "Fresh Look" study of the concept was performed by NASA [5]. The study assumed significant reductions in space launch cost, due to implementation of new technologies for reusable launch vehicles. This study examined a number of altemate concepts [6-10], and considered placing the solar power satellite at locations lower than geosynchronous orbit; drawing the conclusion that other orbits were not practical, since the advantage of geosynchronous orbit, with the power station always in view of the ground station, outweighed the disadvantage of the higher orbit. The study examined microwaves, highfrequency microwaves, and laser [11] transmission of energy. Figure 2 shows one of the many alternate design concepts, the "Power Tower": [5].

The recent increase in energy costs, predictions of the near-term exhaustion of oil, and prominence of possible climate change due to the "greenhouse effect" from burning of fossil fuels has again brought alternative eniergy. sources to public attention, and the time appropriate to reexamine the economics of space based power.

\section{Concept}

A difficulty with the space solar power concept is that the concepts designed in the 1970 s are inherently large in scale (the 1979 baseline design produced $5 \mathrm{GW}$ of power per satellite), and cannot be implemented at smaller sizes. The size limitation results from the size of the microwave transmission aperture needed, since the diffraction-limited spread of the microwave beam transmitting the energy is reduced for large transmitter apertures.

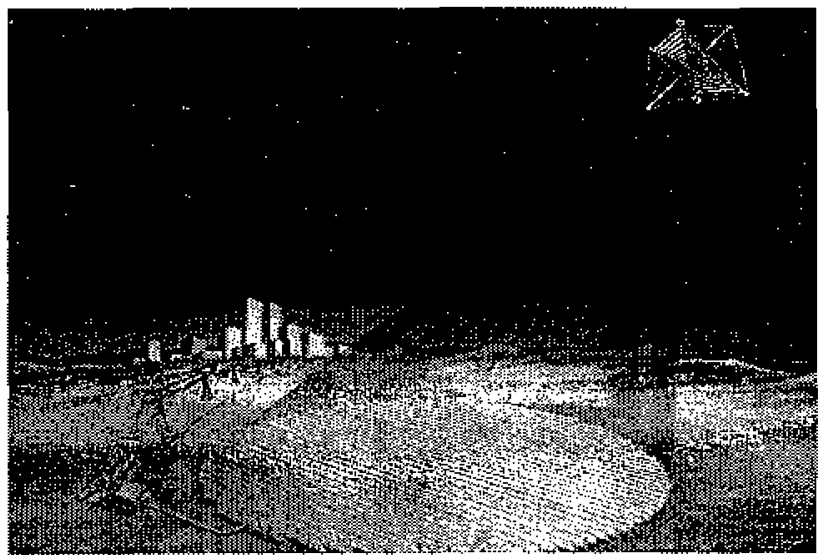

Figure 1: Baseline Solar Power Satellite concept, showing microwave beam being received by a rectenna array. 


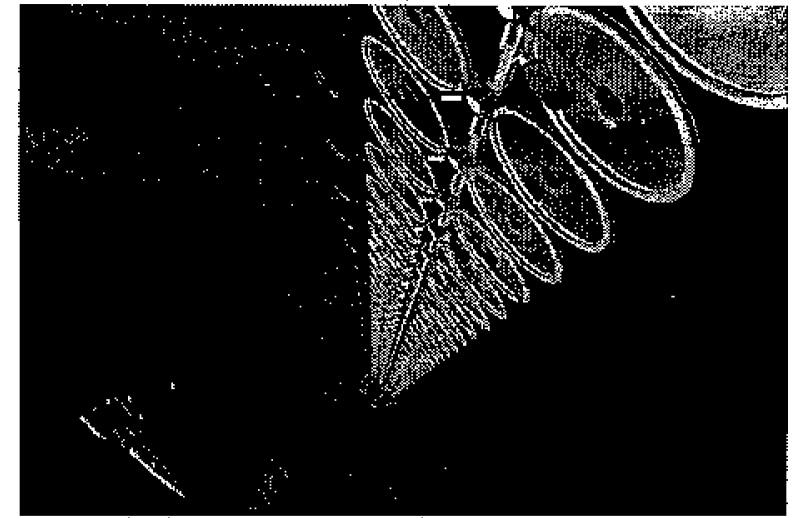

Figure 2: "Power tower" design proposed by the NASA Fresh Look Study [5]. size is

The fundamental formula for the diffraction-limited spot

$$
\mathrm{D}_{\text {spot }}=2.44 \cdot \mathrm{d} \lambda / \mathrm{D}_{\mathrm{trans}}
$$

where $D_{\text {spot }}$ is the diameter of the beam reaching the ground (defined here as the first minimum in the Airy pattern, which contains $86 \%$ of the power), $d$ is the distance transmitted, $\lambda$ is the wavelength, and $D_{\text {trans }}$ is the diameter of the transmitting array. For microwaves at a frequency of $2.45 \mathrm{GHz}, \lambda$ is about $12 \mathrm{~cm}$. A satellite in geosynchronous orbit is $36,000 \mathrm{~km}$ from the surface, and so the rectenna diameter $\mathrm{D}_{\text {rectmina }}$ needed on the ground is $10.5 \mathrm{~km} / \mathrm{D}_{\text {irans. }}$ This does not include the size of the keepout buffer zone around the antenna. For a receiving rectenna on the order of $10 \mathrm{~km}$, a transmitter on the order of a kilometer in diameter is required. At these large sizes, power levels of many GW are required to make the beam power density high enough for efficient conversion. The 1979 baseline design [3] assumed a $1-\mathrm{km}$ diameter transmitting antenna, fed by a $50-\mathrm{km}^{2}$ solar array.

The designs analyzed in the "Fresh Look" study [6], even with extremely optimistic assumptions of system cost; conversion efficiency, and launch cost, resulted in a calculated electricty cost that was not competifive to nearterm prices for baseline electrical power. The calculated cost was either immediately too expensive, or else yields a cost marginally competitive (but not significantly better) than terrestrial power technologies, with an internal rate of return too low for the initial multi-billion dollar investment to make money. Only if an "externality surcharge" is added to non-space power sources to account for the economic impact of fossil fuels did space solar power options make economic sense. While "externality" factors represent a true cost impact of fossil-fuel generation, it is unlikely that the world will impose such charges merely to make space solar power economically feasible.

\section{NEW CONCEPTS FOR SATELLITE POWER SYSTEMS}

The value of the solar power concept (both the dollar value and the potential ecological benefits) is high enough that the concept should not be discarded simply because the initial design proposal is not cost effective.

This paper discusses several approaches to new designs for a solar power satellite, produced as a result of the NASA "Solar Exploratory Fesearch and Technology". (SERT) study program [8-10].

Three basic concepts are suggested: first, creating a design to match the time profile of generated power to the highest-value user requirements; second, making a distributed microwave transmission aperture that is distributed across the solar array and synthesized into a beam using phased-array technology; and third, looking at the synergy between ground and space solar power [12], in order to provide a power system that utilizes the best features of each. The technical details are summarized in references [13-16]. The purpose of this is to create a space solar power concept with a minimum initial cost.

\section{Power Profile}

Past analyses have typically assumed an averaged (or "baseline") power pricing structure. In the real world, price varies with location, season; and time of day; and initial markets for satellite solar electricity need to be selected to maximize revenue. The economic viability of space solar power is maximized if the power can be sold at peak power rates, instead of baseline rate. New designs for a space solar power system were analyzed to provide electrical power to Earth for economically competitive rates. The approach was to look at innovative power architectures to more practical approaches to space solar power. A significant barrier is the initial investment required before the first power is returned.

The market price of electricity to the distribution utility follows the demand. When the demand is low, then the lowest-cost generators are used. At high-demand periods, higher-cost "peak power" generation is required, with spinning reserve needed to deal with instantaneous demand spikes. Figure 3 shows the cost of electrical power in New York City for a typical day in June 2000 [13]. The cost tracks demand: when demand is low, at night, only the low-cost baseline production is required; while when femand is high, higher-cost peaking-power supplies are brought on line to fill the demand. During the lowest demand period, from one to six $\mathrm{AM}_{\mathrm{z}}$ the price is under a quarter of a cent per kilowatt-hour.

\section{Analysis}

Since a solar power satellite beams power long distances, one possibility is to use a single power satellite to provide power to two different geographical markets that are substantially separated in longitude (and hence buy peak-rate power at different times).

If the maximum allowable zenith angle at the receiver is 45 degrees, two locations served by the same geosynchronous orbit solar power satellite can be at most 87 degrees (5.3 hours) apart, as shown in figure 4 . The maximum separation distance is lower if the sites are not on the equator.

This would be sufficient separation to extend the period over which the satellite is providing high-price power from roughly 12 hours per day to roughly 17 hours per day, assuming the ground infrastructure cost is not the major fraction of the power cost.

An alternate approach to providing power at the 
highest value is to simplify the solar power satelite by eliminating sun-tracking, and to fix the orientation to provide power at the most valuable times of day.

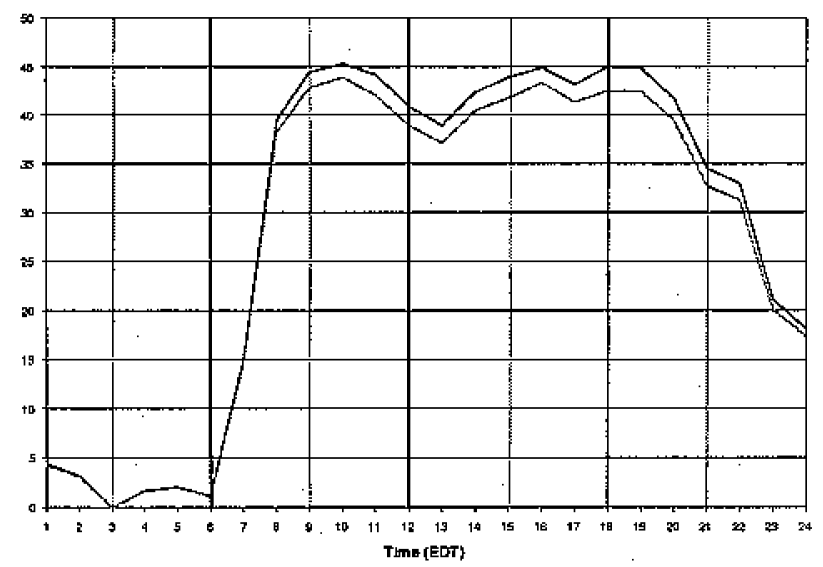

Figure 3: Power Cost (\$/MW--hr) in New York and Hudson Valley as a function of time of day.

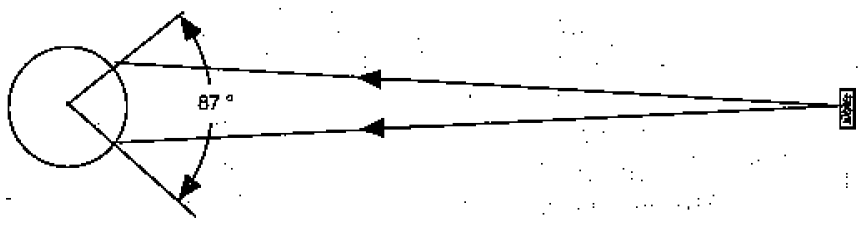

Figure 4. One satellite in geosynchronous orbit can reach ground stations separated by up to 87 degrees.

\section{Fixed orientation SPS}

Baseline designs for solar power satellite systems track the sun, and provide continuous power, except for a period near the spring and autumnal equinox $x_{j}$ when the solar array is eclipsed by the Earth around midnight [1-3].

Since power during the peak period is priced at nearly twice the average price, and power at the off-peak is nearly valueless, it is worth considering whether it might be possible to simplify the power satellite design by eliminating the tracking. A flat-plate, non-tracking solar array will produce only $1 / \pi$ as much power as a tracking satellite, but in principle could be directed to produce that power at the most optimum period of the day, when the value of the power is roughly double the average value. If the reduction in cost due to the gain in simplicity of such a satellite is large, this might be a worthwhile trade.

Figure 5 shows as an example, the power produced by such a fixed orientation solar power satellite, compared with the power demand of New York [13]. Here the peak power level has been selected so that when the satellite produces maximum power production, the generation capacity not met by the space solar power system does not fall below the lowest value during the day.

In the example, this would result in reducing the maximum amount of power produced by the utilities by $850 \mathrm{MW}$, representing a reduction in the peak-power generation capacify needed by the ground utility ("peakshaving") of $4 \%$, Higher power production from the satellite would result in the peak power production at solar noon overfiling the peak demand, and thus, since the (non-solar) production at noon is lower than the lowest night value, the added power from the solar power satellite will be sold at minimum price; rather than maximum. A somewhat higher amount of power can be produced if the satellite is shifted to provide the peak two hours later in the day. A two-hour shift is done by a thirty-degree westward shift in orbital position. Alternately, a $30^{\circ}$ tilt of the orbital array orientation would shift the peak power, or any combination of both.

\section{Power Distribution}

One difficulty of the satellite power system design is the power distribution system in satellite itself. Power distribution is a general problem with all conventional system designs, since at GW power levels, the mass of wire required to link the power generation system to the microwave transmitter becomes unworkable. A design is required in which the solar power can be used directly at the solar array, rather than being sent over wires to a separate transmitter. This problem is solved if a dense phased microwave transmitter array is directly mounted to the solar array [17], however, since the array tracks the sun, such a microwave array would sometimes be face-on or edge-on to the receiver.

A satellite with a non-tracking solar array in fixed orientation with respect to the ground allows the microwave transmitter to be fixed on the array, eliminating the rotary power joint. Since the array is optimally angled at 30 degrees from the ground station, the back of the solar array is always in view by the ground station, and hence the microwave transmission elements can be integrated directly into the back of the array.

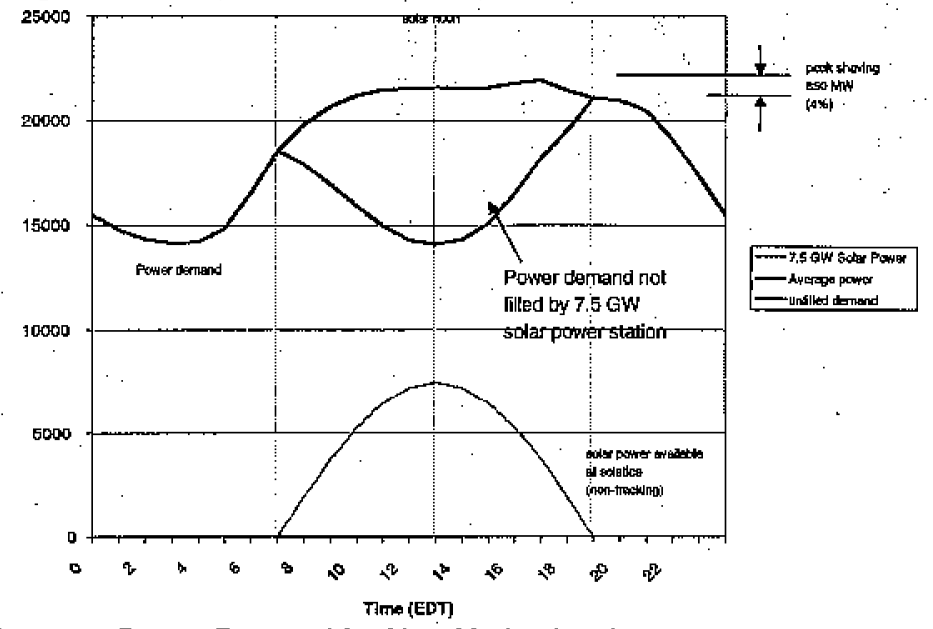

Figure 5: Power Demand for New York, showing a 6.5GW (peak) solar power station used for peak-shaving.

\section{Economic Model}

As a part of the 1995 NASA "Fresh Look" study of space solar power systems, Science Applications International Corporation (SAIC) developed an evaluation tool to use to compare solar power satellite designs with a common set of assumptions. This is a solar power satellite model entitled the Space Segment Model (SSM) 
[7]. The purpose of the SSM is to evaluate the impact of technology and design choices on the mass, performance, and cost of various solar power satellite (SPS) concepts using a common model. The Space Segment Model is a Microsoft Excel 97 workbook consisting of 25 worksheets. The workbook can be used to evaluate the relative cost of different space power architectures, and allows the effect of different assumptions to be evaluated.

The Space Segment Model was used to perform a first-order sizing of the concept. By inputting the desired values of SPS concept, structure type, orbit type, power delivered, photovoltaic cell type, transmitter frequency, etc results of system and subsystem mass and cost were output to the Summary worksheet. Then relevant values in the appropriate sub-system worksheets were altered to botter reflect the proposed design. A standard design was compared with the revised design concept.

Details of the economic spreadsheets were presented at the 3rd Technical Interchange of the SERT project [15].

The result of this analysis shows a total cost of the fixed-orientation design about $36 \%$ lower than the cost of a standard design of similar size. The design produces less total energy, but the power is produced at the peak demand times, and hence serves a higher-price market. By integrating the array with the microwave transmission, the minimum size of the design can be reduced by a factor of eight. This results in nearly an order of magnitude reduction in the initial investment required.

\section{SYNERGY WITH TERRESTRIAL SOLAR}

Although space solar power systems are a technology that competes with large ground based solar installations for the electrical market, space-based and ground-based solar power may well be complementary technologies. Low-cost ground solar power is a necessary precursor to economic viability of space solar power: Space solar power requires low cost, high production and high efficiency solar arrays, and these technologies will make ground solar attractive for many markets. The ground solar power market, in turm, will serve to develop technology and the high-volume production readiness for space solar power [11]. Both techriologies can be implemented at large scale, each one providing power to the segment of the market to which it is best adapted.

It is desirable to consider how space power will interface with the ground-based solar infrastructure. Synergies include:

1. Integrate solar and microwave receivers on ground. This will allow the space solar power to use the land footprint, power conditioning and distribution networks put in place for ground power installations.

2. Use solar power satellites to beam to receivers when ground solar is unavailable. By "filling in" power when ground solar is unavailable, space solar power will serve as the complement to solar.

\section{CONCLUSIONS}

The concept of a space solar power system that provides power to terrestrial markets by microwave beam has some advantages as an approach to large-scale solar electrical power generation, but has many technical and political barriers before it can become economically feasible. A new conceptual approach to the design of the satellite solar power station is outlined, with the advantages of a lower initial cost and a better fit of the power generation profile to the user requirements.

\section{REFERENCES}

[1] P. E. Glaser, "Power from the Sun: Its Future," Science Vol. $162,957-961$ (1968).

[2] P. E. Glaser, F. P. Davidson, and K. I. Csigi (eds.), Solar Power Satellites: The Emerging Energy Option, John Wiley \& Sons Inc (June 1994; second edition 1998).

[3] NASA, Satellite Power System Concept Development and Evaluation Program. System Definition Technical Assessment Report, U.S. Department of Energy, Office of Energy Research, Report DOE/ER/10035-03, Dec. 1980.

[4] U. S. Office of Technology Assessment, Solar Power Satellites, 1981.

[5] J. Mankins, "A Fresh Look At Space Solar Power; New Architecture, Concepts, and Technologies," paper IAF-97-R.2.03, 48th International Astronautical Conference, October 6-10 1997, Turin, Italy.

[6] H. Feingold et al, Space Solar Power: A Fresh Look at the Feasibility of Generating Solar Power in Space, SAIC Report 97/1005, contract NAS3-26565, April 1997.

[7] H. Feingold, Space Solar. Power - 1998 Concept Definition Study, Science Applications International Corp., Futron Corporation, Contract NAS3-26565; Feb., 1999.

[8] Proc. Space Solar Power Advanced Concepts -Study Project Technical Interchange Meeting, Sept. 19-20 1995.

[9] Space Solar Power (SSP) Exploratory Research and Technologies (SERT) Program Technical Interchange Meeting 2, Univ. Alabama; Huntsville AL, Dec. 7-10 1999.

[10] Space Solar Power (SSP) Explóratory Research and Technologies (SERT) Program, Technical Interchange Meeting 3, Univ. Alabama, Huntsville AL, June 212000.

[11] G. Landis, "Photovoltaic Receivers for Laser Beamed Power," 22nd IEEE Photovoltaic Specialists Conference, Las Vegas NV, Oct. 1991, Vol. II, 1494-1502.

[12] G. Landis, "An Evolutionary Path to SPS," Space Power, Vol. 9 No. 4, pp. 365-371 (1990).

[13] G. Landis, "Peak Power Markets for Satelite Solar Power," paper IAC-02-R.3.06, $53^{\text {rd }}$ Intemational Astronautical Congress, Houston TX, October 10-19 2002. [14] G. Landis, "Reinventing the Solar Power Satellite," paper |AC-02-R.1.07, $3^{\text {th }}$ Intemational Astronautical Congress, Houston TX, Oct. 10-19 2002 (see also ref [15]) [15] G. Landis, "Reinventing the Solar Power Satelite," NASA Technical Memorandum TM-2004-212743 (2004).

[16] G. Landis, "Advanced Design Concepts: Synergy of Ground and Space Solar Power," Space Solar Power (SSP) Exploratory Research and Technologies (SERT) Program, Technical Interchange Meeting 3, University of Alabama, Huntsville AL, June 21, 2000.

[17] G. Landis and R. Cull, "Integrated Solar Power Satellites: An Approach to Low-Mass Space Power," Space Power, Vol. 11, No. 3-4, 303-218 (1992). 